\title{
Vitamin D: A Review and Proposed Evidence for Treatment or Prevention in COVID-19
}

\author{
Nimesh Sing ${ }^{1 *}$, Bharat Suthar ${ }^{1}$, Abhay Mehta ${ }^{1}$, Sandeep Shukla ${ }^{2}$ and Archna Pandey ${ }^{2}$ \\ ${ }^{1}$ Flax Laboratories, M.H., India \\ ${ }^{2}$ Department of Chemistry, Dr. H.S. Gour University, M.P., India
}

*Corresponding author: Nimesh Singh, Flax Laboratories, B-29/1, Mahad MIDC, Taluka- Mahad, Distt - Raigad, Maharashtra, India

\begin{abstract}
WHO declared COVID-19 a worldwide pandemic. The ambitions of this paper are to assess if there is any affiliation between mean levels of diet $D$ in various countries and cases respectively mortality because of COVID-19. Low vitamin $\mathrm{D}$ repute in winter allows viral epidemics. During iciness, those who do not take Vitamin D supplements are possibly to have low serum 25-hydroxyvitamin D [25(OH)D] (25-hydroxyvitamin D) concentrations. Vitamin $D$ can reduce the chance of viral epidemics and pandemics in numerous approaches. First, better $25(\mathrm{OH}) \mathrm{D}$ concentrations lessen the chance of many continual illnesses, together with cancers, cardiovascular sickness, continual respiratory tract infections (RTIs), diabetes mellitus, and high blood pressure. Patients with continual sicknesses have a drastically higher threat of dying from RTIs than otherwise wholesome human beings. $2 d$, Vitamin $D$ reduces the risk of rites thru three mechanisms: Keeping tight junctions, killing enveloped viruses through induction of cathelicidin and defenses, and reducing the production of pro-inflammatory cytokines by means of the innate immune machine, thereby decreasing the hazard of a cytokine hurricane leading to pneumonia. Observational and supplementation trials have pronounced higher $25(\mathrm{OH}) \mathrm{D}$ concentrations associated with decreased threat of dengue, hepatitis, herpes virus, hepatitis $b$, and $c$ viruses, human immunodeficiency virus, influenza, breathing syncytial virus infections, and pneumonia. Effects of a community discipline trial pronounced herein indicated that 25(OH)D concentrations above $50 \mathrm{ng} / \mathrm{ml}(125 \mathrm{nmol} / \mathrm{l})$ vs. $<20 \mathrm{ng} / \mathrm{ml}$ have been associated with a $27 \%$ discount in influenza-like ailments. From the available evidence, we hypothesize those raising serum 25(Oh)D concentrations through Vitamin D supplementation may want to lessen the occurrence, severity, and chance of dying from influenza, pneumonia, and the cutting-edge COVID-19 epidemic.
\end{abstract}

\author{
Keywords \\ COVID-19, Corona virus, Vitamin D, Cholecalciferol, Cal- \\ citriol
}

\section{Introduction}

Vitamin $D$ is a gathering of fat-solvent secosteroids liable for expanding intestinal assimilation of calcium, magnesium, and phosphate, and numerous other organic effects [1]. In people, the most significant mixes in this gathering are Vitamin D3 (otherwise called cholecalciferol) and Vitamin D2 (ergocalciferol) [2].

The significant regular wellspring of the nutrient is a combination of cholecalciferol in the lower layers of skin epidermis through a substance response that is reliant on sun presentation (explicitly UVB radiation) $[3,4]$. Cholecalciferol and ergocalciferol can be ingested from the eating routine and from supplements $[2,5,6]$. Only a couple of nourishments, for example, the tissue of greasy fish, normally contain huge measures of Vitamin $D[7,8]$. In the U.S. what's more, different nations, dairy animals' milk, and plant-inferred milk substitutes are sustained with Vitamin D, as are many breakfast grains. Mushrooms presented to bright light contribute helpful measures of Vitamin D [7]. Dietary proposals normally expect that the entirety of an individual's Vitamin $D$ is taken by mouth, as sun presentation in the populace is variable and suggestions about the measure of sun introduction that is sheltered are questionable taking into account the skin malignant growth risk [7].

Citation: Singh N, Suthar B, Mehta A, Shukla S, Pandey A (2020) Vitamin D: A Review and Proposed Evidence for Treatment or Prevention in COVID-19. Int J Virol AIDS 7:064. doi.org/10.23937/2469567X/1510064

Received: May 21, 2020: Accepted: June 18, 2020: Published: June 20, 2020

Copyright: (C) 2020 Singh N, et al. This is an open-access article distributed under the terms of the Creative Commons Attribution License, which permits unrestricted use, distribution, and reproduction in any medium, provided the original author and source are credited. 
Respiratory tract diseases are conditions that influence the air sections. These incorporate intense contaminations that influence the lower respiratory tract and lungs, for example, pneumonia and flu [8], which are among the main sources of death in kids overall [9]. In $2015,16 \%$ of all passings in youngsters under fiveyears-old were credited to pneumonia [9]. These conditions may likewise affect personal satisfaction [10]. In this way, it is essential to discover mediations that could forestall respiratory conditions.

Vitamin $D$ is a fat-dissolvable nutrient, not quite the same as others in that a significant source gets from UV light-incited change of its antecedent under the skin. Dietary sources incorporate braced nourishments and enhancements. Studies have shown that there is a high pervasiveness of Vitamin D insufficiency overall $[11,12]$. Vitamin D lack may influence the resistant framework as Vitamin D assumes an immune-modulation job [13], improving natural invulnerability by up-managing the articulation and discharge of antimicrobial peptides [7-16], which supports mucosal barriers. Besides, late meta-examinations have announced a defensive impact of Vitamin D supplementation on respiratory tract contaminations [17-20]. Subsequently, in this critique, we investigated the materialness of such intercession and execution in settings with constrained assets dependent on these four efficient surveys and meta-examinations.

As stated earlier that WHO pronounced SARS-CoV-2 a worldwide pandemic. Little is thought about the potential defensive variables. Past examinations recognized a relationship between more elevated levels of ACE2 and better coronavirus illness wellbeing results. In the lung, ACE2 secures against intense lung injury [21]. Calcitriol (1,25-dihydroxyvitamin D3) applies pronouncedly impacts on ACE2/Ang(1-7)/MasR hub with the upgraded articulation of ACE2 [22]. The essential points of this investigation are to survey if there is any relationship between the mean degrees of Vitamin $D$ in different nations and the mortality brought about by COVID-19. The optional point was to distinguish if there is any relationship between the mean Vitamin D levels in different nations and the number of instances of COVID-19.

The connection between Vitamin $D$ insufficiency and vulnerability to disease has been recommended for longer than a century, with the early perception that youngsters with dietary rickets were bound to encounter contaminations of the respiratory framework, prompting the instituting of the adage "rachitic lung" [23]. The segregation of Vitamin D3 from cod liver oil, which was utilized to treat tuberculosis (TB) during the 1930s, prompted it's across the board use in TB treatment and anticipation until the presentation of anti-infective chemotherapy during the 1950s [24]. All the more as of late, epidemiologic investigations have exhibited solid relationship between regular varieties in Vitamin D levels and the frequency of different irre- sistible illnesses, including septic stun [25], respiratory disease [26], and flu [27,28].

Our comprehension of Vitamin D digestion and its extra skeletal capacities has improved impressively during the previous 3 decades. The revelation that Vitamin $D$ receptor (VDR) and $1 \alpha$-hydroxylase, the chemical vital for change of Vitamin D into its dynamic structure, are available in cells of the safe framework, including flowing mononuclear cells $[29,30]$, has reformed the field of Vitamin D immunology. Besides, the revelation of nonskeletal elements of Vitamin D has revitalized enthusiasm for Vitamin $D$ as a potential modulator in an assortment of malady states [31-33]. Late investigations have shown that Vitamin D manages the declaration of explicit endogenous antimicrobial peptides in invulnerable cells [34]; this activity prompts a potential job for Vitamin $D$ in regulating the insusceptible reaction to different irresistible infections.

\section{Vitamin D and Bacterial Infections}

The spearheading work by Rook, et al. [33] and Crowle, et al. [34] during the 1980s showed that Vitamin D upgraded bactericidal action of human macrophages against Mycobacterium tuberculosis, the causative operator of TB. This revelation prompted another period of enthusiasm with respect to the job of Vitamin $D$ in deciding pathogenesis and the resistant reaction to bacterial pathogens. Liu, et al. [32] gave a key component to how Vitamin D may upgrade intrinsic invulnerability. This gathering showed that incitement of macrophage-bound Toll-like receptor $2 / 1$ complex by $M$ tuberculosis-determined antigens up regulates the outflow of both VDR and CYP27b1, a compound that changes over 25-hydroxyvitamin $D(25-\mathrm{OHD})$ to its dynamic 1,25-dihydroxy vitamin $D[1,25-(\mathrm{OH}) 2 \mathrm{D}]$ structure. Intracellular 1,25-(OH)2D produced however activity of CYP27b1 then communicates with the VDR and prompts enlistment of the antimicrobial peptide cathelicidin and executing of intracellular M. tuberculosis [11]. In the condition of Vitamin $D$ lack, the contaminated macrophage can't create adequate $1,25-(\mathrm{OH}) 2 \mathrm{D}$ to up regulate the creation of cathelicidin [35].

\section{Vitamin D and Upper Respiratory Tract Viral Infections}

Four of the 7 previously mentioned examinations assessed the recurrence of respiratory tract contamination or flu in Vitamin D-treated patients in correlation with control subjects $[36,37]$. An early preliminary by Rehman [38] most intently takes after a case-control study; 27 kids were chosen based on a clinical history of repetitive respiratory or anti-infection requiring ailment and combined with age-coordinated control subjects recorded to be liberated from intermittent contamination. The ensuing investigation uncovered the repetitive disease gathering to have a lot higher commonness of subclinical rickets (that is, pediatric Vitamin D lack) and 
a diminished repeat of respiratory contamination after a course of forceful Vitamin $D$ repletion, given as 60,000 IU week by week for about a month and a half (28). In spite of its promising outcomes, in any case, the investigation is dependent upon a few traps, including the nonappearance of a fake treatment control arm, constrained example size, and restricted documentation with respect to the adequacy of the picked Vitamin D repletion routine, which may influence the generalizability and in the general translation of the results [35].

\section{COVID-19 and Vitamin D Supplementation}

Vitamin $D$ is a steroid hormone created by the skin during summer introduction to UVB beams. Hypovitaminosis $D$ is basic in winter (October to March) at Northern scopes over 20 degrees north, and from April to September at Southern scopes past 20 degrees beneath the equator.

Previously, coronaviruses and flu infections have displayed high regularity, with episodes happening especially throughout the winter. The Covid-19 pandemic is in fact increasingly serious above winter scopes of 20 degrees, while it stays up to this pointless extreme in the Southern half of the globe, with a much lower number of passing. Research additionally shows that Vitamin D assumes a job in adjusting RAS and in lessening lung harm. Despite what might be expected, ceaseless hypovitaminosis $D$ incites pneumonic fibrosis through the initiation of RAS. Thus, hypovitaminosis $D$ has been unequivocally related in the writing with ARDS, just as with a pejorative indispensable guess in revival yet in addition to geriatric units, and with different related to passing's during COVID-19 diseases. On the other hand, Vitamin D supplementation has been accounted for to expand.

High-portion oral Vitamin D3 supplementation has been appeared to diminish transient mortality in revival patients with serious hypovitaminosis D (17\% total hazard decrease). It is viewed as protected to take oral Vitamin D supplementation at dosages up to $10,000 \mathrm{IU} /$ day for brief periods, especially in more seasoned grownups, for example, a populace that is generally influenced by hypovitaminosis $D$ and who ought to get at any rate $1,500 \mathrm{IU}$ of Vitamin D every day to guarantee palatable Vitamin D status.

Vitamin D supplementation is referenced as a conceivably intriguing treatment for COVID-19 contamination however consistently with a low degree of proof as of not long ago. We theorize that high-portion Vitamin D supplementation improves the visualization of more seasoned patients determined to have COVID-19 contrasted with a standard portion of Vitamin D [39].

\section{In Vitro Proof for Vitamin D's Job in Insuscep- tibility and Disease}

There is in vitro proof that Vitamin D is associated with insusceptible cell reactions to some popular and bacterial respiratory pathogens. Vitamin $D$ appears to up regulate qualities engaged with reactions in resistant cells that are presented to Streptococcus pneumonia [40]. There are research facility contemplates indicating that respiratory epithelial cells can change over Vitamin $D$ to its dynamic structure and that Vitamin D metabolites increment cytokines engaged with insusceptibility in light of respiratory infections. Be that as it may, Vitamin D metabolites don't appear to forestall viral replication in cell societies [13,41-46].

\section{Clinical Evidence in Covid-19}

We searched PubMed and Google Scholar for studies that included terms for vitamin D and COVID-19. We found no trials of vitamin D in COVID-19 that has reported results. We did find several studies that are registered, but have not yet reported. None seemed to be masked comparisons to placebo.

\section{Conclusion}

Vitamin D supplementation for forestalling respiratory tract disease isn't routinely done. For this intercession to be successful, it ought to be done ceaselessly, before the respiratory tract disease begins. This could be a significant test in numerous under-resourced settings, as program directors and strategy creators should get ready for the obtainment of the arrangement, stockpiling, dissemination, quality control, and consistent confirmation of Vitamin D supplements for youngsters on a standard premise. Disappointments in the execution of this intercession have been ascribed in numerous occurrences to the deficient framework and poor consistency, especially in creating nations. Irregular Vitamin D supplementation would decrease a portion of these difficulties, in spite of the fact that outcomes from these preliminaries show that bolus dosages are not compelling. Future examinations could assess the viability of various dosing plans on respiratory tract contaminations, for example, when seven days, which might be simpler to actualize.

Taking everything into account, we discovered noteworthy rough connections between Vitamin $D$ levels and the number of COVID-19 cases and particularly the mortality brought about by this disease. The most helpless gathering of the populace for COVID-19, the maturing populace, is likewise the one that has the most shortfall Vitamin D levels.

Vitamin D has just been appeared to ensure against intense respiratory diseases and it was demonstrated to be sheltered. It ought to be fitting to perform devoted examinations about Vitamin D levels in COVID-19 patients with various degrees of malady seriousness.

\section{Further Research}

Extra preliminaries testing distinctive dosing regimens (level of portion and interims) are required before 
executing this at a populace level. Likewise, preliminaries ought to catch up members sufficiently long to comprehend if Vitamin D is as yet viable once Vitamin D status is ideal, as once Vitamin D insufficiency is remedied, giving more Vitamin $D$ supplementation may not give extra advantages. As of now, there are other randomized controlled preliminaries testing the impacts of $\mathrm{Vi}$ tamin $D$ on the danger of intense respiratory tract contamination, which could help explain a portion of these issues. Also, future examinations need to report adherence to the mediation to more readily comprehend if the incorporation of non-follower members would inclination the outcomes revealed up until this point.

\section{References}

1. Holick MF (2004) Sunlight and vitamin D for bone health and prevention of autoimmune diseases, cancers, and cardiovascular disease. Am J Clin Nutr 80: 1678S-1688S.

2. Holick MF (2006) High prevalence of vitamin D inadequacy and implications for health. Mayo Clin Proc 81: 353-373.

3. MacDonald J (2019) How does the body make vitamin d from sunlight? JSTOR Daily.

4. Holick MF, MacLaughlin JA, Clark MB, Holick SA, Potts JT, et al. (1980) Photosynthesis of previtamin D3 in human skin and the physiologic consequences. Science 210: 203-205.

5. Calvo MS, Whiting SJ, Barton CN (2005) Vitamin D intake: A global perspective of current status. J Nutr 135: 310-316.

6. Norman AW (2008) From vitamin D to hormone D: Fundamentals of the vitamin $D$ endocrine system essential for good health. Am J Clin Nutr 88: 491S-499S.

7. (2016) Vitamin D Fact Sheet for Health Professionals. National Institutes of Health (NIH).

8. WHO (2016) Respiratory tract diseases. Geneva: World Health Organization.

9. WHO (2016) Pneumonia. Geneva: World Health Organization.

10. Jiang X, Sun L, Wang B, Yang X, Shang L, et al. (2013) Health-related quality of life among children with recurrent respiratory tract infections in Xi'an, China. PLoS One 8: e56945.

11. Palacios C, Gonzalez (2014) Is vitamin D deficiency a major global public health problem?. J Steroid Biochem Mol Biol 144: 138-145.

12. Wahl DA, Cooper C, Ebeling PR, Eggersdorfer M, Hilger J, et al. (2012) A global representation of vitamin D status in healthy populations. Arch of Osteoporos 7: 155-172.

13. Greiller CL, Martineau AR (2015) Modulation of the immune response to respiratory viruses by vitamin D. Nutrients 7 : 4240-4270.

14. Wang TT, Dabbas B, Laperriere D, Bitton AJ, Soualhine $\mathrm{H}$, et al. (2010) Direct and indirect induction by 1,25-dihydroxyvitamin D3 of the NOD2/CARD15-defensin beta2 innate immune pathway defective in Crohn disease. J Biol Chem 285: 2227-2231.

15. Gombart AF, Borregaard N, Koeffler HP (2005) Human cathelicidin antimicrobial peptide (CAMP) gene is a direct target of the vitamin $\mathrm{D}$ receptor and is strongly up-regulated in myeloid cells by 1, 25-dihydroxyvitamin D3. FASEB J 19: 1067-1077.
16. Yakoob MY, Salam RA, Khan FR, Bhutta ZA (2016) Vitamin $D$ supplementation for preventing infections in children under five years of age. Cochrane Database Syst Rev 11: CD008824.

17. Bergman $P$, Lindh ÅU, Björkhem-Bergman L, Lindh JD (2013) Vitamin D and respiratory tract infections: a systematic review and meta-analysis of randomized controlled trials. PLoS One 8: e65835.

18. Charan J, Goyal JP, Saxena D, Yadav P (2012) Vitamin D for prevention of respiratory tract infections: a systematic review and meta-analysis. J Pharmacol Pharmacother 3: 300-303.

19. Martineau AR, Jolliffe DA, Hooper RL, Greenberg L, Aloia JF, et al. (2017) Vitamin D supplementation to prevent acute respiratory tract infections: Systematic review and meta-analysis of individual participant data. BMJ 356: 6583.

20. Kuka K, Imai Y, Penninger JM (2006) Angiotensin-converting enzyme 2 in lung diseases. Curr Opin Pharmacol 6: 271-276.

21. Cui C, Xu P, Li G, Qiao Y, Han W, et al. (2019) Vitamin D receptor activation regulates microglia polarization and oxidative stress in spontaneously hypertensive rats and angiotensin II-exposed microglial cells: Role of renin-angiotensin system. Redox Biol 26: 101295.

22. Khajavi A, Amirhakimi GH (1977) The rachitic lung: Pulmonary findings in 30 infants and children with malnutritional rickets. Clin Pediatr (Phila) 16: 36-38.

23. Martineau AR, Honecker FU, Wilkinson RJ, Griffiths CJ (2007) Vitamin D in the treatment of pulmonary tuberculosis. J Steroid Biochem Mol Biol 103: 793-798.

24. Danai PA, Sinha S, Moss M, Haber MJ, Martin GS (2007) Seasonal variation in the epidemiology of sepsis. Crit Care Med 35: 410-415.

25. Grant WB (2008) Variations in vitamin D production could possibly explain the seasonality of childhood respiratory infections in Hawaii. Pediatr Infect Dis J 27: 853.

26. Cannell JJ, Vieth R, Umhau JC, Holick MF, Grant WB, et al. (2006) Epidemic influenza and vitamin D. Epidemiol Infect 134: 1129-1140.

27. Bhalla AK, Amento EP, Clemens TL, Holick MF, Krane SM (1983) Specific high-affinity receptors for 1,25-dihydroxyvitamin D3 in human peripheral blood mononuclear cells: Presence in monocytes and induction in T lymphocytes following activation. J Clin Endocrinol Metab 57: 1308-1310.

28. Stumpf WE, Sar M, Reid FA, Tanaka Y, DeLuca HF (1979) Target cells for 1,25-dihydroxyvitamin D3 in intestinal tract, stomach, kidney, skin, pituitary, and parathyroid. Science 206: $1188-1190$

29. Cantorna MT, Mahon BD (2004) Mounting evidence for vitamin $\mathrm{D}$ as an environmental factor affecting autoimmune disease prevalence. Exp Biol Med (Maywood) 229: 11361142.

30. Wactawski-Wende J, Kotchen JM, Anderson GL, Assaf AR, Brunner RL, et al. (2006) Calcium plus vitamin D supplementation and the risk of colorectal cancer. $\mathrm{N}$ Engl $\mathrm{J}$ Med 354: 684-696.

31. Flanagan JN, Young MV, Persons KS, Wang L, Mathieu JS, et al. (2006) Vitamin D metabolism in human prostate cells: Implications for prostate cancer chemoprevention by vitamin D. Anticancer Res 26: 2567-2572.

32. Liu PT, Stenger S, Li H, Wenzel L, Tan BH, et al. (2006) Toll-like receptor triggering of a vitamin D-mediated human 
antimicrobial response. Science 311: 1770-1773.

33. Rook GA, Steele J, Fraher L, Barker S, Karmali R, et al. (1986) Vitamin D3, gamma interferon, and control of proliferation of Mycobacterium tuberculosis by human monocytes. Immunology 57: 159-163.

34. Crowle AJ, Ross EJ, May MH (1987) Inhibition by 1,25 $(\mathrm{OH}) 2$-vitamin D3 of the multiplication of virulent tubercle bacilli in cultured human macrophages. Infect Immun 55: 2945-2950.

35. Yamshchikov AV, Desai NS, Blumberg HM, Ziegler TR, Tangpricha V (2009) Vitamin D For Treatment And Prevention Of Infectious Diseases: A Systematic Review Of Randomized Controlled Trials. Endocr Pract 15: 438-449.

36. Avenell A, Cook JA, Maclennan GS, Macpherson GC (2007) Vitamin D supplementation to prevent infections: A sub-study of a randomised placebo-controlled trial in older people (RECORD trial, ISRCTN 51647438). Age Ageing 36: 574-577.

37. Li-Ng M, Aloia JF, Pollack S, Cunha BA, Mikhali M, et al. (2009) A randomized controlled trial of vitamin D3 supplementation for the prevention of symptomatic upper respiratory tract infections. Epidemiol Infect 137: 1396-1404.

38. Rehman PK (1994) Sub-clinical rickets and recurrent infection. J Trop Pediatr 40: 58.

39. (2020) Covid-19 and Vitamin D Supplementation: A Multi- center Randomized Controlled Trial of High Dose Versus Standard Dose Vitamin D3 in High-risk COVID-19 Patients (CoVitTrial).

40. Hansdottir S, Monick M, Hinde S, Lovan N, Look D, et al. (2008) Respiratory Epithelial Cells Convert Inactive Vitamin D to its Active Form. J Immunol 181: 7090-7099.

41. Olliver M, Spelmink L, Hiew J, Meyer-Hoffert U, Henriques-Normark B, et al. (2013) Immunomodulatory effects of vitamin $D$ on innate and adaptive immune responses to Streptococcus pneumoniae. J Infect Dis 208: 1474-1481.

42. Martin Kohlmeier (2020) Avoidance of vitamin D deficiency to slow the COVID-19 pandemic. bmjnph.

43. Nema N, Pandey A, Singh N, Suthar B, Mehta A (2020) Corona Virus: An Immunological Perspective Review. Int J Immunol Immunother 7: 1-6.

44. Pandey A, Singh N, Shukla S (2020) Re-Infection and Immunological effect of Corona Virus: A Detailed Review. Indo Global Journal of Pharmaceutical Sciences 10: 25-32.

45. Mehta A, Singh N, Pandey A, Suthar B (2020) Spike protein based vaccine and chemical drugs: Futuristic weapon to fight against pendemic covid 19. Alochana Chakra Journal 9: $36-42$.

46. Aloia JF, Li-Ng M (2007) Re: Epidemic influenza and vitamin D. Epidemiol Infect 135: 1095-1096. 